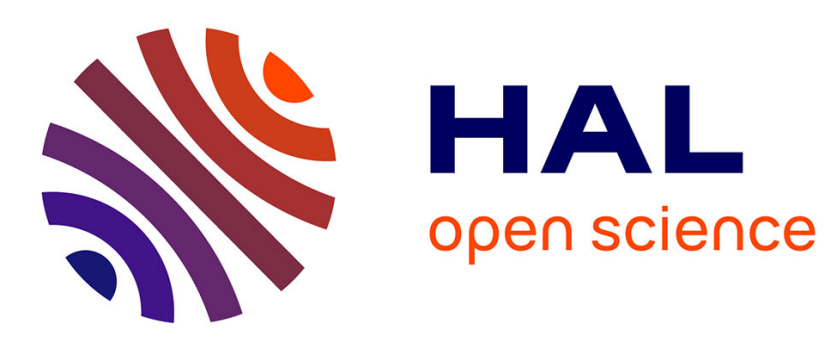

\title{
Influence of Power Converter Losses Evaluation in the Sizing of a Hybrid Renewable Energy System
}

Miguel Lopez, Dario Morales, Jean-Claude Vannier, Daniel Sadarnac

\section{To cite this version:}

Miguel Lopez, Dario Morales, Jean-Claude Vannier, Daniel Sadarnac. Influence of Power Converter Losses Evaluation in the Sizing of a Hybrid Renewable Energy System. International Conference On Clean Electrical Power, 2007, Capri, Italy. 6 p. hal-00243105

\section{HAL Id: hal-00243105 \\ https://hal-centralesupelec.archives-ouvertes.fr/hal-00243105}

Submitted on 6 Feb 2008

HAL is a multi-disciplinary open access archive for the deposit and dissemination of scientific research documents, whether they are published or not. The documents may come from teaching and research institutions in France or abroad, or from public or private research centers.
L'archive ouverte pluridisciplinaire HAL, est destinée au dépôt et à la diffusion de documents scientifiques de niveau recherche, publiés ou non, émanant des établissements d'enseignement et de recherche français ou étrangers, des laboratoires publics ou privés. 


\title{
Influence of Power Converter Losses Evaluation in the Sizing of a Hybrid Renewable Energy System
}

\author{
M. López, D. Morales, J.-C. Vannier, and D. Sadarnac \\ Département Energie de l'École Supérieure d'Electricité; 3 rue Joliot-Curie, Gif-sur-Yvette (France)
}

\begin{abstract}
An improvement to the precision of losses calculation in static converters used in a hybrid renewable energy system (HRES) is presented in this article. The objective is to be able to evaluate energy losses in the system during the unit sizing process. The models developed in this paper consider the conduction and switching losses to take into account the variation of the converters efficiency together with the load variations. The proposed approach for the energy losses calculation is tested with an already sized HRES. The methodology is compared on an hour-byhour basis with a constant efficiency rate approach using a specially developed simulation program. The importance of the correct energy losses evaluation is demonstrated.
\end{abstract}

Index Terms-power conversion losses, power generation, solar energy, wind energy

\section{NOMENCLATURE}

$r_{D}$

$V_{D}$

$I_{D}$

$i_{D R M S}$

$p_{D}$

$r_{T}$

$V_{T}$

$I_{T}$

$i_{T R M S}$

$p_{T}$

$p_{R}$

$D$

$t_{o n}$

$t_{\text {off }}$

$I_{L}$

$i_{L R M S}$

$p_{d c / d c}$

$I_{m}$

$M$

$\varphi$

$p_{d c / a c}$

$I_{N}$

$t_{r N}$

$t_{f N}$

$t_{r r N}$

$Q_{r r N}$

$f_{s}$
Diode internal forward resistance $(\Omega)$

Diode forward voltage threshold (V)

Diode average current (A)

Diode effective current (A)

Diode conduction losses (W)

Transistor internal forward resistance $(\Omega)$

Transistor forward voltage threshold (V)

Transistor average current (A)

Transistor effective current (A)

Transistor conduction losses (W)

Rectifier conduction losses (W)

DC/DC converter duty cycle (-)

DC/DC converter transistor on-state time (s)

DC/DC converter transistor off-state time (s)

$\mathrm{DC} / \mathrm{DC}$ converter average current (A)

$\mathrm{DC} / \mathrm{DC}$ converter effective current (A)

DC/DC converter conduction losses (W)

Converter steady-state maximal current (A)

Inverter modulation index (-)

Inverter load angle (rad)

Inverter conduction losses (W)

Converter nominal current (A)

Switch turn-on time at nominal conditions (s)

Switch turn-off time at nominal conditions (s)

Nominal reverse recovery time (s)

Nominal reverse recovery charge (C)

Converter switching frequency $(\mathrm{Hz})$

This work was supported by the Chilean Government and the Ecole Supérieure d'Electricité. $\begin{array}{ll}p_{c, \text { on }} & \text { Turn-on switching losses (W) } \\ p_{c, \text { off }} & \text { Turn-off switching losses (W) } \\ p_{r r} & \text { Recombination losses (W) }\end{array}$

\section{INTRODUCTION}

A Hybrid Renewable Energy Systems (HRES) is a power generation system composed of two or more energy sources where at least one of them is of renewable origin. Applications in this type of system include water pumping through DC motors operating centrifugal pumps, vaccine storage, rural electrification in developing countries, etc; particularly in isolated places were to dispose energy from the grid is expensive or even impossible [1]-[2].

To motivate the use of HRES, an appropriate assessment for unit sizing a renewable energy system must be made in order to reduce the overall cost of the energy produced while achieving acceptable reliability conditions. In general, energy losses of the wind turbine (WT), diesel generator (DG) and photovoltaic (PV) panels are estimated with some level of accuracy in order to calculate the total amount of energy supplied by each source. The energy losses of the power converters become an important issue in unit sizing of renewable energy systems because of its influence on the total energy delivered to the load. For many years, authors have treated the problem of the energy losses estimation in power converters [3], [4], [5] in a wide scope of applications but not specifically in the renewable energy systems area. Previously, some efforts have been made in order to take into account the energy losses in power converters within a unit sizing procedure. In [6] and [7], an iterative approach inside the unit sizing procedure is proposed using constant efficiency rates.

In this article, a new approach to estimate the energy losses in the power electronics converters is proposed. The equations are developed considering the special characteristics of a small hybrid renewable energy systems and its operation. A DG, WT, PV solar modules, and a battery bank compose the hybrid system. The unit sizing procedure takes into account the economical aspects of each generating unit and stochastic nature of renewable energy sources. The energy losses estimation is included within the unit sizing procedure. The results are compared with a constant efficiency approach. 
This paper begins with the description of the proposed models. The next section describes the models developed to estimate the conduction losses in the rectifier and the switching and conduction losses in the inverter and the PV's maximum power point tracker (MPPT). In the fourth section, the simulation results are shown in order to display the application of the proposed models. Finally, some conclusions and perspectives of this work are exposed.

\section{PROPOSED METHOD}

\section{A. System description}

The system under study contains a three-phase DG connected through a rectifier to the DC bus, a WT also connected to the DC bus through a diode bridge, PV solar panels with a Maximum Power Point Tracker (MPPT), a battery bank for energy storage and back-up, and one inverter to transfer the required power to the load. The system is shown in Fig. 1.

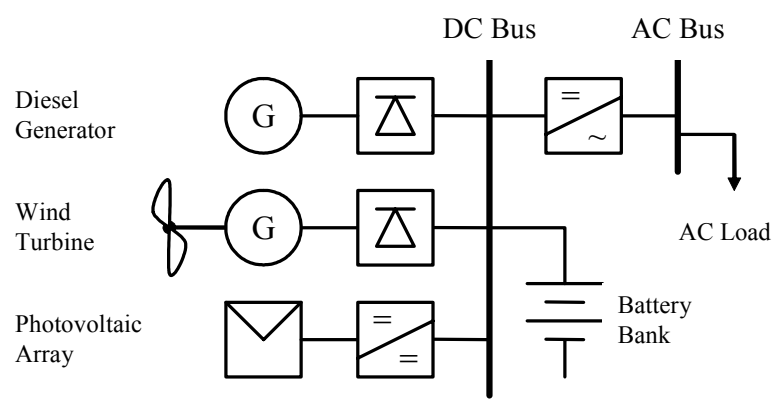

Fig. 1. Hybrid renewable energy system composed of wind and photovoltaic power sources, a diesel generation unit, a battery bank and one inverter.

There are two power transformers in the system. One is a three-phase step-down transformer that connects the DG to the rectifier and the other is a single-phase step-up transformer that connects the inverter output to the system electric load. In this study, as transformers are operating at low-voltage and low-frequency, iron losses are neglected. Therefore, since only the copper losses are taken in account, the transformers are modeled as simple equivalent series impedances.

The load has a nominal voltage of $220 \mathrm{~V} / 50 \mathrm{~Hz}$ as well as the DG (phase-to-neutral voltage). Power MOSFETs are used as switches in the controlled power electronics converters. The switching frequency of the PWM converters is chosen at $20 \mathrm{kHz}$, for audible noise cancellation, at low EMI and low switching losses. For security reasons, the DC bus voltage is 48 Volts. To avoid annoying effects on the system load, a passive harmonic filter is connected at the inverter output. This filter is considered to be ideal, so it is free of energy losses.

\section{B. Unit Sizing Procedure}

The procedure to make an economic choice of the size of each generating unit is based on the minimization of the life cycle cost that implies an economic analysis over the lifetime of the project. A supplementary procedure for sizing the storage battery and the DG is used.

In order to evaluate the quality of the design, a simulation program was specially developed. To calculate the hourly energy flow, the mathematical models for the WT and the PV solar panels are used. Wind speed and solar irradiance data are needed to calculate the total energy produced by the wind turbine and the solar module. Their Probability Distribution Function (PDF) characterizes the behavior of these variables.

One important step in the unit sizing procedure is the energy non supplied (ENS) calculation. In this step, the right estimation of the energy losses in the system is a key point. Detailed information about the unit sizing procedure can be found in [7].

\section{Energy Losses Calculation}

The analysis is made taking into account the wave forms of voltages and currents in the system.

The proposed HRES AC/DC converters connected between the DC bus and the wind turbine and the diesel generator are simple three-phase diode bridges, thus only conduction losses are considered. The DC/DC converter connected between the solar panels and the DC bus, and the inverter connected between the $\mathrm{DC}$ and the $\mathrm{AC}$ buses are switch-mode operated converters. In this case, the switching frequency is much higher than the system's frequency. Therefore, switching losses are not negligible and must be calculated.

\section{Diode Conduction Losses}

The diode's model used to evaluate on-state losses in power electronic converters is shown in Fig. 2, where $r_{D}$ is the ON-state diode resistance and $V_{D}$ is the threshold forward voltage necessary to put the diode in conduction state. These parameters are characteristics of the diode.

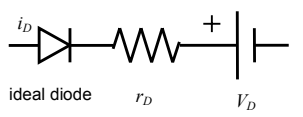

Fig. 2. Diode model for $\mathrm{ON}$ state losses calculation

Conduction losses in each diode can be calculated as follows, where $I_{D}$ is the average diode current and $i_{D}$ RMS is the effective diode current.

$$
p_{\text {diode }}=V_{D} \cdot I_{D}+r_{D} \cdot i_{D R M S}^{2}
$$

\section{E. Power transistors Conduction Losses}

Gate-controlled switching semiconductors are used to modulate the static power converters of the proposed hybrid system. The switch-mode converters are the PV array maximum power point tracker (MPPT), implemented with a DC/DC converter, and the inverter that feeds the hybrid system ac load.

A simple general model for transistor on-state is used to evaluate conduction losses. It is analog to the previous 
diode model, but changing the ideal diode for and ideal unidirectional switch. This model can be applied to both IGBT and MOSFET power transistors, where $V_{O N}$ is set to 0 when using a MOSFET. Thus, on-state transistor losses in both switching power converters of the HRES can be calculated by (2).

$p_{T}=V_{O N} \cdot I_{T}+r_{O N} \cdot i_{T R M S}^{2}$

\section{F. Diode Bridge Rectifier Conduction Losses}

The diode bridge generates distorted line currents and/or voltages depending on the load and/or source characteristics. For a strong power source, like a large utility grid, with a high inductive DC load, the output current is nearly constant and line currents have a sixpulse shape [8]. But in the case under study, the DC bus has a battery bank that behaves like a constant DC voltage source, thus like a high capacitive load. Fig. 3 shows the electrical scheme from the generator to the DC bus. Moreover, the source is a small diesel or wind generator that usually has high inductive windings. Therefore, supposing the generator voltage and inductances sufficiently important, the source currents are nearly sinusoidal. The line voltage has the 6 pulses shape, with a maximal value given by the battery bank voltage.

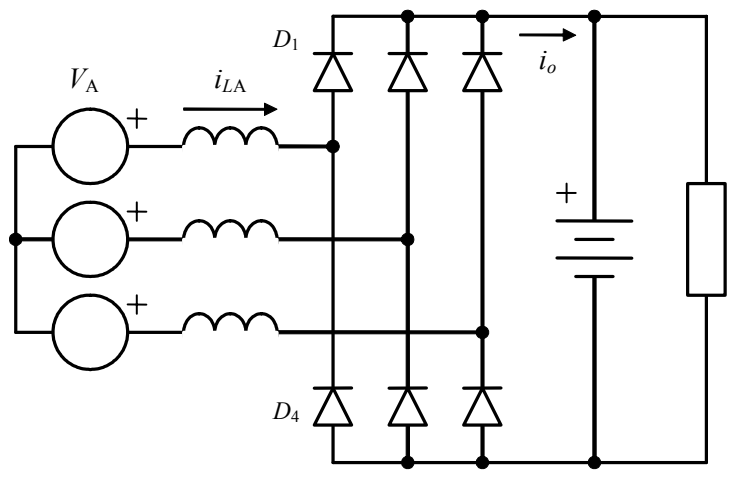

Fig. 3. Three-phase bridge diode rectifier with a high inductive electrical power source and a high capacitive DC load

These sinusoidal currents flow through the diodes. To evaluate conduction losses with (1), it is necessary to calculate the average and effective values of the diode currents. These values can be expressed in terms of the input line current $i_{L}(3)$, or in terms of the DC output current $I_{o}$ (4). These expressions are valid for continuous mode of conduction; i.e., the current in one diode extinguishes only because other diode begins its conduction cycle and the output current value is always higher than zero. This is very probable due to inductive behavior of the source. Fig. 4 shows the rectifier AC input currents in one phase (composed of diode currents $i_{D 1}$ and $\left.i_{D 4}\right)$ and the output current $i_{o}$.

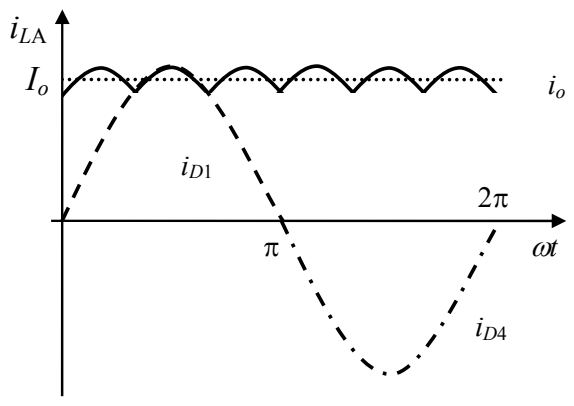

Fig. 4. Diode bridge current waveforms; input line current $i_{L \mathrm{~A}}$ composed by $i_{D 1}$ and $i_{D 4}$ currents and output current $i_{o}$

$$
\begin{aligned}
& I_{D}=\frac{\sqrt{2}}{\pi} i_{L}=\frac{1}{3} I_{o} \\
& i_{D, R M S}=\frac{\sqrt{2}}{2} i_{L}=\frac{\pi}{6} I_{o}
\end{aligned}
$$

Since every diode have similar characteristics and the normal operation of the rectifier implies equal but 120 degrees out-of-phase currents in all components, conduction losses can be expressed as follows (5), (6).

$$
\begin{aligned}
& p_{R}\left(i_{L}\right)=6 \cdot p_{\text {diode }}=\frac{6 \sqrt{2}}{\pi} \cdot V_{D} \cdot i_{L}+3 \sqrt{2} \cdot r_{D} \cdot i_{L}^{2} \\
& p_{R}\left(I_{o}\right)=6 \cdot p_{\text {diode }}=2 \cdot V_{D} \cdot I_{o}+\frac{\pi^{2}}{6} \cdot r_{D} \cdot I_{o}^{2}
\end{aligned}
$$

\section{G. DC/DC Converter Conduction Losses}

The following conduction losses analysis is made for a one single-stage DC/DC power converter; i.e., only one transistor-diode pair is used for the DC/DC conversion. Continuous current mode is assumed in the converter operation; i.e., the main current flows without extinguishing through the power semiconductors for each conduction state. The transistor conducts the converter current during "ON" state $\left(t_{O N}\right)$ and the diode the converter current in the "OFF" state $\left(t_{\text {off }}\right) . D$ is the transistor duty cycle [8]. In Fig. 5, the transistor, the diode and the inductor current shapes for two switching cycles are shown. From this figure, equations for the average and effective currents of the transistor and the diode (8) and (9) are obtained. $I_{T}, I_{D}$, and $I_{L}$ are respectively the transistor, diode and inductance average currents and $i_{T, R M S}, i_{D, R M S}$ and $i_{L, R M S}$ are the transistor, diode and inductance effective currents.

$$
\begin{array}{ll}
D=\frac{t_{\text {on }}}{T} & T=t_{\text {on }}+t_{\text {off }} \\
I_{T}=D \cdot I_{L} & i_{T, R M S}=\sqrt{D} \cdot i_{L, R M S} \\
I_{D}=(1-D) \cdot I_{L} & i_{D, R M S}=\sqrt{1-D} \cdot i_{L, R M S}
\end{array}
$$




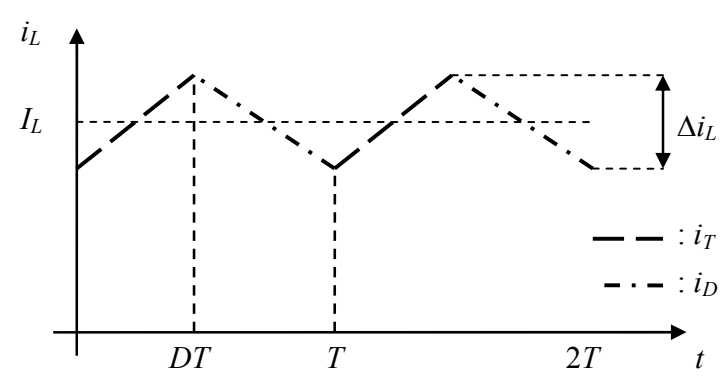

Fig. 5. Steady state inductor current waveform $i_{L}$ composed by transistor and diode currents $\left(i_{T}, i_{D}\right)$ for two cycles of a one single step DC/DC converter

Conduction losses in basic switching converters occur in both state conditions; during ON-state, the power transistor wastes some energy and during OFF-state, the freewheeling diode generates the power dissipation. Replacing correspondently (8) and (9) in conduction losses equations (1) and (6), (10) and (11) are obtained. By adding these last equations, conduction losses in the basic DC/DC converter can be calculated with (12).

$$
\begin{aligned}
p_{T}=D \cdot\left(V_{T, O N} \cdot I_{L}+r_{O N} \cdot i_{L, R M S}^{2}\right) \\
p_{D}=(1-D) \cdot\left(V_{D, O N} \cdot I_{L}+r_{D} \cdot i_{L, R M S}^{2}\right) \\
p_{d c / d c}=\left(\begin{array}{r}
\left(D \cdot V_{T, O N}+(1-D) \cdot V_{D, O N}\right) \cdot I_{L}+ \\
\left(D \cdot r_{T, O N}+(1-D) \cdot r_{D}\right) \cdot i_{L, R M S}^{2}
\end{array}\right.
\end{aligned}
$$

The static converter's DC current $i_{L}$ and effective current $i_{L, R M S}$ are not equal because there is an alternative triangular shape component $i_{L, A C}$ of the inductor current created by transistor to diode current switching, charging and discharging the inductor alternatively (Fig. 5). This $\mathrm{AC}$ component is proportional to current ripple $\Delta i_{L}$ and it is dependent of the converter switching frequency $f_{S}$ and the inductance value $L$, among others converter parameters.

The DC/DC converter design for continuous conduction mode generally limits $\Delta i_{L}$ to a specific percentage of the DC current (between 5 or 10 percent of inductor current). The worst case happens when converter operation is in the border of discontinuous mode; i.e., the main current extinguishes at the end of the switching period in steady state. This is a $200 \%$ of ripple in converter current, an unusual high value for continuous mode design considerations. Anyway, even if this happens, the effective current $i_{L, R M S}$ is only $15,5 \%$ higher than average current $I_{L}$. Therefore, supposing this worst case, (12) can be expressed as (13).

$$
\begin{aligned}
& p_{d c / d c}=\left(D \cdot V_{T, O N}+(1-D) \cdot V_{D, O N}\right) \cdot I_{L}+ \\
& \frac{4}{3}\left(D \cdot r_{T, O N}+(1-D) \cdot r_{D}\right) \cdot I_{L}
\end{aligned}
$$

\section{H. Inverter Conduction Losses}

The hybrid system in study is designed to supply energy to a small single-phase isolated load, so a simple $\mathrm{H}$-Bridge inverter is proposed to deliver regulated $\mathrm{AC}$ voltage from the DC bus (Fig. 6). To simplify the design and to minimize the size of the output filter that connects the inverter and the load, pulse-width-modulation (PWM) control is used. Thus, losses are produced by conduction and switching in the semiconductors. So, as in the $\mathrm{DC} / \mathrm{DC}$ converter, these two kinds of energy losses must be calculated.

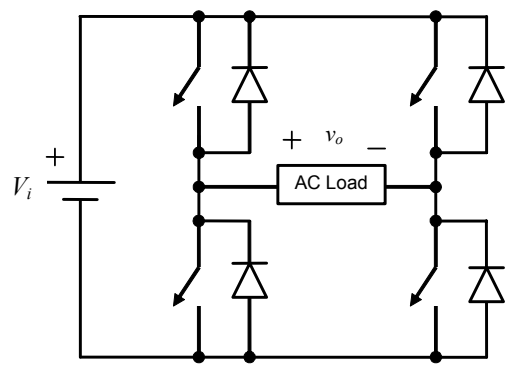

Fig. 6. HRES inverter power circuit

The analytical method proposed in [4] is used to evaluate the PWM inverter conduction losses. With (14) and (15) conduction losses for one transistor-diode pair are calculated. These are expressed in terms of semiconductor characteristics $\left(r_{D}, V_{D}, r_{T}, V_{T}\right)$ and converter variables like maximal current $I_{m}$, modulation index $M$ and load angle $\varphi$. For the H-structure DC/AC converter (16) calculates total conduction losses.

$$
\begin{aligned}
& p_{T}=\frac{V_{T} I_{m}}{2 \pi}\left(1+\frac{\pi}{4} M \cos \varphi\right)+\frac{r_{T} I_{m}^{2}}{2 \pi}\left(\frac{\pi}{4}+\frac{2 M}{3} \cos \varphi\right) \\
& p_{D}=\frac{V_{D} I_{m}}{2 \pi}\left(1-\frac{\pi}{4} M \cos \varphi\right)+\frac{r_{D} I_{m}^{2}}{2 \pi}\left(\frac{\pi}{4}-\frac{2 M}{3} \cos \varphi\right) \\
& p_{d c / a c}=4\left(p_{T}+p_{D}\right)
\end{aligned}
$$

\section{Switching Losses}

Many distinct variables influence this kind of losses in static converters: temperature, current, semiconductor material, etc. In the study of a system composed of at least one PWM controlled converter, switching losses can not be neglected when the system losses are calculated.

The analytic approach to calculate losses during commutation proposed in [5] is used in this article. This model considers the most important components of these losses for evaluation: turn-on losses $P_{c, \text { on }}$, turn-off losses $P_{c, \text { off }}$, and recombination losses $P_{r r}$. To make this calculation, it is necessary to know the maximal blockage voltage $V_{m}$, maximal and nominal currents $I_{m}$ and $I_{N}$, the converter switching frequency $f_{S}$ and the raise and fall times at nominal conditions $t_{r N}$ and $t_{f N}$. To estimate recombination losses it is also necessary to know the nominal recombination time $t_{r r N}$ and charge $Q_{r r N}$. The hybrid system PWM converters switching losses are evaluated using (17) - (19).

$$
p_{c, o n}=\frac{1}{8} V_{m} \frac{I_{m}^{2}}{I_{N}} t_{r N} f_{s}
$$




$$
\begin{aligned}
p_{c, \text { off }} & =V_{m} I_{m} t_{f N} f_{s}\left(\frac{1}{3 \pi}+\frac{1}{24} \frac{I_{m}}{I_{N}}\right) \\
p_{r r}= & V_{m} f_{s}\left[\left(\frac{0.8}{\pi}+0.05 \frac{I_{m}}{I_{N}}\right) \cdot I_{m} t_{r r N}\right. \\
& \left.+\left(0.28+\frac{0.38}{\pi} \frac{I_{m}}{I_{N}}+0.015\left(\frac{I_{m}}{I_{N}}\right)^{2}\right) \cdot Q_{r r N}\right]
\end{aligned}
$$

\section{Results}

The proposed approach for the energy losses calculation is tested with an already sized HRES. The methodology is compared on an hour-by-hour basis with a constant efficiency rate approach using a specially developed simulation program.

The daily average solar radiation on a horizontal surface in the selected place is $4.61 \mathrm{kWh} / \mathrm{m}^{2}$ and the average wind speed is $6.1 \mathrm{~m} / \mathrm{s}$. The hourly load profile for one day is shown in Fig. 7.

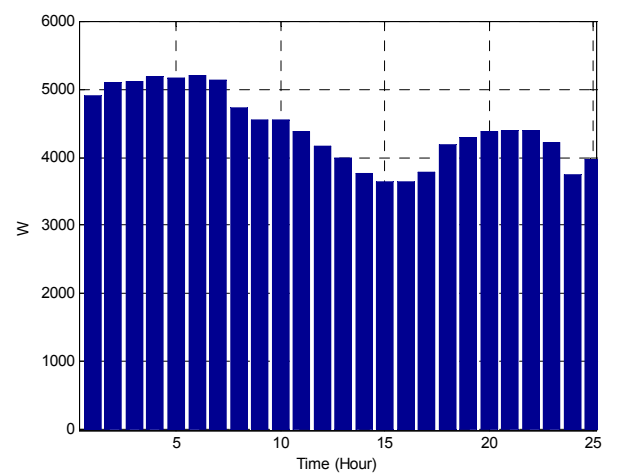

Fig. 7. Hourly load profile for one typical day.

The energy production of the HRES for the constant efficiency rate and for the proposed variable efficiency rate approaches are shown in Figures 8 and 9 respectively. Each power source generation is plotted for each hour of the day, for a typical day. The state of charge of the battery bank is also shown, as well as the load profile and the energy balance. From the latter the ENS value is obtained by integration of the negative values.

In the constant efficiency rate approach, the efficiency of all power converters is set at $90 \%$. The system is first simulated using this constant efficiency rate approach. The energy supplied by each generating unit and the energy demanded by the load are shown in Fig. 8. The diary total lack of energy is $13.8 \mathrm{kWh}$.

The system is then simulated using the proposed losses calculation approach for calculating energy losses in the HRES. Fig. 9 shows the energy supplied by each generating unit and the energy demanded by the load. The lower efficiency rates calculated using the proposed methodology give as result a diary total lack of energy equal to $34,5 \mathrm{kWh}$. In this case, the calculated energy non supplied to the load (ENS) is about $40 \%$ higher when used the proposed method.

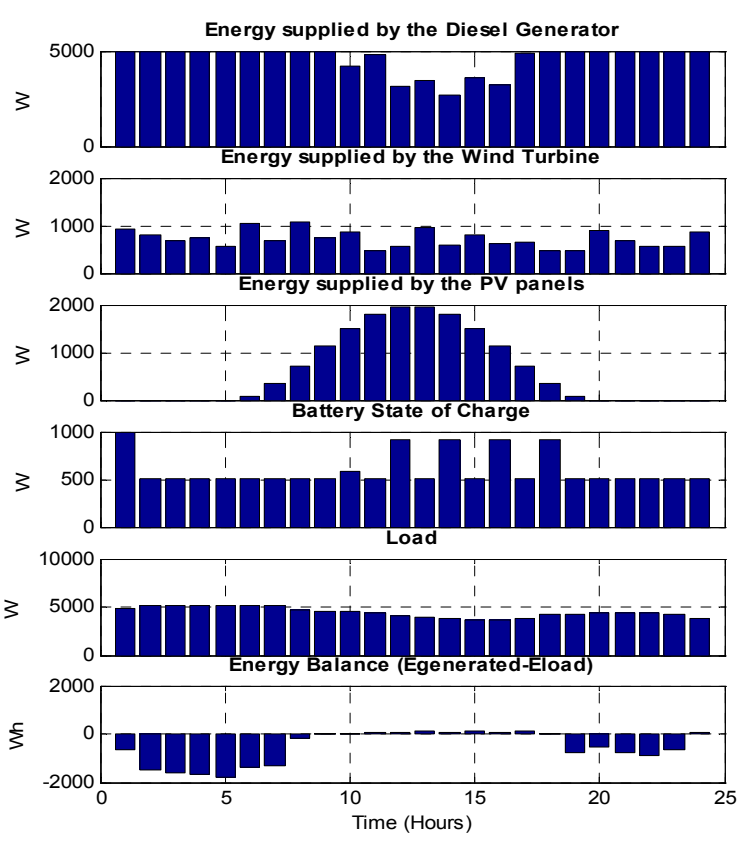

Fig. 8. HRES energy production for 24 hours of a typical day at constant efficiency rates. Different power sources generation, the battery state of charge, load profile and energy balance.

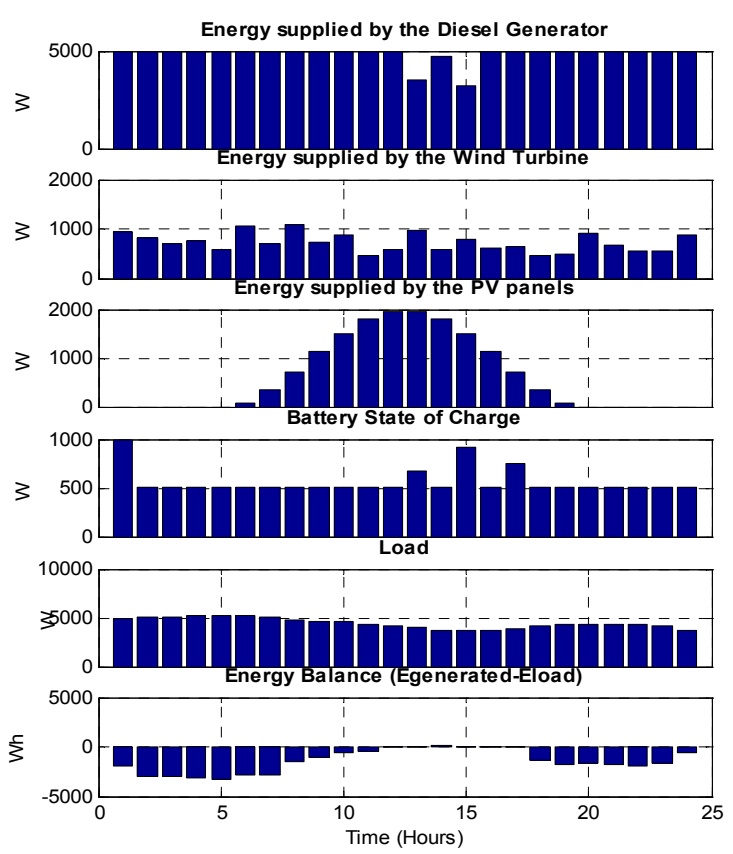

Fig. 9. HRES energy production for 24 hours of a typical day at variable efficiency rates (proposed evaluation). Different power sources generation, the battery state of charge, load profile and energy balance.

This large difference in ENS estimation is explained by an overall efficiency lower than the $90 \%$ supposed in the constant efficiency method; this way, the total energy delivered by the HRES is lower than expected and, 
therefore, the lack of energy is higher. The more accurate evaluation of losses done by the proposed method includes operating points other than nominal, where efficiency is lower most of the time. It includes also most of losses in all power converters (transformers and electronic devices); thus, a higher ENS calculation was expected and finally obtained.

From the analysis of the results it can be seen that the energy losses calculation have a significant effect over the calculation of the long-term system performance. The right estimation of parameters such as the energy non supplied to the load is important when unit sizing a renewable energy system and are strongly influenced by the total energy losses.

\section{CONCLUSION}

In the analysis of renewable energy systems, the constant efficiency approach is generally used when analyzing the long-term system's behavior. This is especially important when more precise losses estimation is needed in order to calculate the available energy that can be delivered to the load. In this article, a novel approach for the energy losses calculation in a HRES is proposed.

The proposed method allows taking into account variable energy losses during the system operation. Models for the conduction and switching energy losses are used and adapted to the special characteristic of each power electronic converter in the system. Assumptions on the system operation are made in order to obtain analytical expressions for the power converter energy losses. The proposed method is then compared with the constant efficiency rate approach. It can be noticed that using the constant efficiency approach one could underestimate the total energy losses in the system.

Related to the energy losses calculation, only one possible system topology is analyzed in this article. The work can be continued including new topologies and new equipments. Also, the DC bus voltage can be elevated in order to reduce the value of the current and so the total energy losses.

\section{APPENDIX}

The principal parameters of the system are summarized in the following table:

TABLE I

SUMMARY OF THE HRES PARAMETERS

\begin{tabular}{|c|r|}
\hline Diesel Generator & $220 \mathrm{~V}$ \\
\hline Rated voltage & $5000 \mathrm{~W}$ \\
\hline Rated power & \\
\hline Rectifier Diodes & $800 \mathrm{~V}$ \\
\hline Rated voltage & $10 \mathrm{~A}$ \\
\hline Rated current & $1.1 \mathrm{~V}$ \\
\hline Conduction voltage & $20 \mathrm{~m} \Omega$ \\
\hline Conduction resistance & \\
\hline MOSFET & $150 \mathrm{~V}$ \\
\hline Rated voltage & \\
\hline
\end{tabular}

\begin{tabular}{|c|r|}
\hline Average current & $60 \mathrm{~A}$ \\
\hline Conduction voltage & $0 \mathrm{~V}$ \\
\hline Conduction resistance & $0.04 \Omega$ \\
\hline$t_{r N}, t_{f N}$ & $40 \mathrm{~ns}, 40 \mathrm{~ns}$ \\
\hline$t_{r r N}, Q_{r r N}$ & $150 \mathrm{~ns}, 2.0 \mu \mathrm{C}$ \\
\hline Fast recovery diodes & $200 \mathrm{~V}$ \\
\hline Rated voltage & $20 \mathrm{~A}$ \\
\hline Average current & $1.3 \mathrm{~V}$ \\
\hline Conduction voltage & $12.5 \mathrm{~m} \Omega$ \\
\hline Conduction resistance & \\
\hline Transformers & $6000 \mathrm{~W}$ \\
\hline Three-phase step-down & $0.05 \Omega$ \\
\hline Rated power & \\
\hline Equivalent resistance & $5000 \mathrm{~W}$ \\
\hline Single-phase step-up & $0.15 \Omega$ \\
\hline Rated power & \\
\hline Equivalent resistance & $14 \mathrm{~m} / \mathrm{s}$ \\
\hline Wind turbine & $3.7 \mathrm{~m}$ \\
\hline Rated wind speed & $3.0 \mathrm{~kW}$ \\
\hline Rotor diameter & $150 / 900 \mathrm{rpm}$ \\
\hline Rated power & $3 \mathrm{~kW}$ \\
\hline Rotor speed & $36 \mathrm{~V}$ \\
\hline Solar Panels (18 180W-panels) & $5 \mathrm{~A}$ \\
\hline Peak power & \\
\hline Rated voltage & \\
\hline Rated current & \\
\hline
\end{tabular}

\section{ACKNOWLEDGMENT}

The authors would like to thank the Chilean Government and the Ecole Supérieure d'Electricité (Supelec) for their economical support in this research. Mr. Miguel Lopez is a "Presidente de la Republica de Chile" scholarship holder for his doctoral studies.

\section{REFERENCES}

[1] R. Chedid and S. Rahman, "Unit Sizing and Control of Hybrid Wind-Solar Power Systems", IEEE Trans. Energy Conversion, vol. 12, No.1, 1997, pp. 79-85.

[2] B. S. Borowy and Z. M. Salameh, "Optimum Photovoltaic Array Size for a Hybrid Wind/PV System", IEEE Trans. Energy Conversion, vol. 9, No.3, 1994, pp.482-488.

[3] Liberti, G.; Mazzucchelli, M.; Puglisi, L.; Sciutto, G. "Estimation of losses in static power converters via computer simulation: preliminary results". Internat. Journal of Energy Systems, vol. 8, 1998, pp. 13-16.

[4] M.H. Bierhoff, F.W. Fuchs, "Semiconductor Losses in Voltage Source and Current Source IGBT Converters Based on Analytical Derivation", Proc. of the Power Electronics Society Conference, 2004.

[5] F. Casanellas, "Losses in PWM inverters using IGBTs", IEE Proc. Electric Power Applications, Vol. 141, No.5, September 1994, pp. 235-239.

[6] D. Morales and J-C. Vannier, "Conception et simulation d'une installation mixte d'énergie électrique renouvelable". Proc. of the EF Conference, 2003.

[7] D. Morales and J-C. Vannier, "Unit Sizing of Small Hybrid Renewable Energy Conversion Systems Under Uncertainty", Proc. of the ICEM'04, 2004.

[8] Mohan, Undeland, and Robbins. "Power Electronics: Converters, Applications, and Design", John Wiley \& Sons, 2th Ed., 1995. 